\title{
Exploring the Research Ethics Domain for Postgraduate Students in Computing
}

\author{
Kay Fielden \\ UNITEC Institute of Technology, Auckland, New Zealand
}

Kfielden@unitec.ac.nz

\begin{abstract}
In this paper Nicholson's (1994) four-fold conceptual framework has been applied to ethical issues in research by postgraduate students undertaking theses or dissertations in computing. Ethical dilemmas are explored showing how knowledge in this area is acquired, shared and integrated from one research project to the next and within any one postgraduate cohort. Ethics of performing research within computing rather than professional codes are discussed. A major challenge in raising the level of awareness of professional ethics is in encouraging students to make the upwards shift from not only learning and applying technical skills but also integrating these skills with knowledge of the larger social system in which technology sits. A broad overview of how research ethics is practiced by postgraduate students undertaking thesis or dissertation is also discussed.
\end{abstract}

Keywords: Ethics, postgraduate research

\section{Introduction}

Achieving ethical practice with postgraduate research students is a multi-faceted and complex process requiring clear direction and exemplary role modelling. A shift in emphasis is needed to balance a positivist with a human-centred approach to research ethics. Postgraduate research projects for Masters in Computing students at UNITEC involve a range of both qualitative and quantitative research methods, all of which have a host of ethical principles.

Most professional sectors - including computing - have adopted codes of ethical practice. There are many codes of ethics for computing professionals including those laid out by Association for Computing Machinery (ACM), Institute of Electrical and Electronics Engineers, Inc (IEEE) and The Computer Societies from Australia, New Zealand, Hong Kong and Britain, (www.ccsr.cse.dmu.ac.uk). Baase (1997, p. 332) has described computer ethics as "professional ethics similar to medical, legal and accounting ethics". Baase also states computer ethics as ethical issues faced by a computer professional as part of the job. While codes of ethics and professional practice have been formulated (IEEE-CS/ACM Joint Task Force on Software Engineering Ethics and Professional Practice, 1998) little is espoused directly in the Information Systems literature on the adherence of computer ethics (Cassidy, 1998); rather, it is implied in the strategic

Material published as part of this journal, either on-line or in print, is copyrighted by Informing Science. Permission to make digital or paper copy of part or all of these works for personal or classroom use is granted without fee provided that the copies are not made or distributed for profit or commercial advantage AND that copies 1) bear this notice in full and 2) give the full citation on the first page. It is permissible to abstract these works so long as credit is given. To copy in all other cases or to republish or to post on a server or to redistribute to lists requires specific permission from the publisher at Publisher@InformingScience.org directions for research ethics that are aligned with core business strategies (Hirscheim, Klein, \& Lytinnen, 1995; Pierce \& Henry, 1996).

The Masters in Computing program consists of either half course-work, half thesis or three quarters coursework and one quarter dissertation. The 
course work includes a double credit point research methods paper in which ethics is taught as a component of the curriculum.

This paper does not consider such professional codes, but rather the ethics of performing research within computing. Such postgraduate research is usually - but not always - applied research involving interaction with professionals in the industry. The postgraduate research is a guided process that includes interaction with the academic world of supervision, research proposal approval and ethical approval. Applying Nicholson's (1994) four-level framework for conceptualizing ethical behavior within an organizational context to research ethics highlights the dilemmas faced by the neophyte researcher in applied computing.

This paper includes a broad overview of how research ethics is practiced by postgraduate students undertaking thesis or dissertation. While Nicholson's (1994) framework is explored fully, the main focus is the ethical process in performing postgraduate research.

\section{Nicholson's (1994) Four-Level Conceptual Framework}

Nicholson (1994) has proposed a four-level conceptual framework to link themes within organizational literature to give some research direction in this field. These four levels are ethical domains, ethical functioning, ethical process and ethical condition. Ethical domains are further divided into exogenous and endogenous (external and internal) environments, linkages, stewardship, values and interpersonal. Table 1 shows Nicholson's framework applied to postgraduate (PG) research for students, supervisors and the higher education institution.

\section{Ethical Domains}

Ethical domains denote the orientation of the organization in relation to goals and strategies and how these relate to the internal and external environments (Table 1). Issues relating to dependence, threat, uncertainty, complexity and volatility, according to systems theories may all have bearing on the environment in which the organization operate. Of particular concern when considering research into applied computing are risk management issues about how information systems operate within the business world.

\section{External and internal environments}

Ethical domains maybe divided into two classes -- exogenous and endogenous, corresponding to contingencies in the external and internal environments. This is a simplistic view of the environment as being two discrete classes - the internal ethical environment, colored and shaped by client attitudes and organizational conflicts as well as by wider social structures and norms; while external forces such as regulatory frameworks and institutional practices also determine ethical domains both internal and external. Exogenous forces bearing on the ethics of an organization arise from its dependence on major stakeholders and interest groups; the existence of social norms and pressure on organizations also exerts social responsibility through their acts and products. Students in the Masters in Computing program are likely to delve into both internal and external ethical domains. For this reason it is most advisable for these students to be equipped with a deeper understanding of ethical domain issues.

\section{The PG research ethics domain}

The ethical domain for postgraduate research in applied computing is complex and interconnected. The underlying assumption is that postgraduate students undertaking thesis or dissertation would have acquired the societal ethics that is necessary to build an understanding of professional ethics prior to enrolling. Whilst the graduate school academic committee approves postgraduate research that this research must have institutional ethical approval is not to be assumed. With a 
Table 1 Nicholson's Framework applied to PG Research

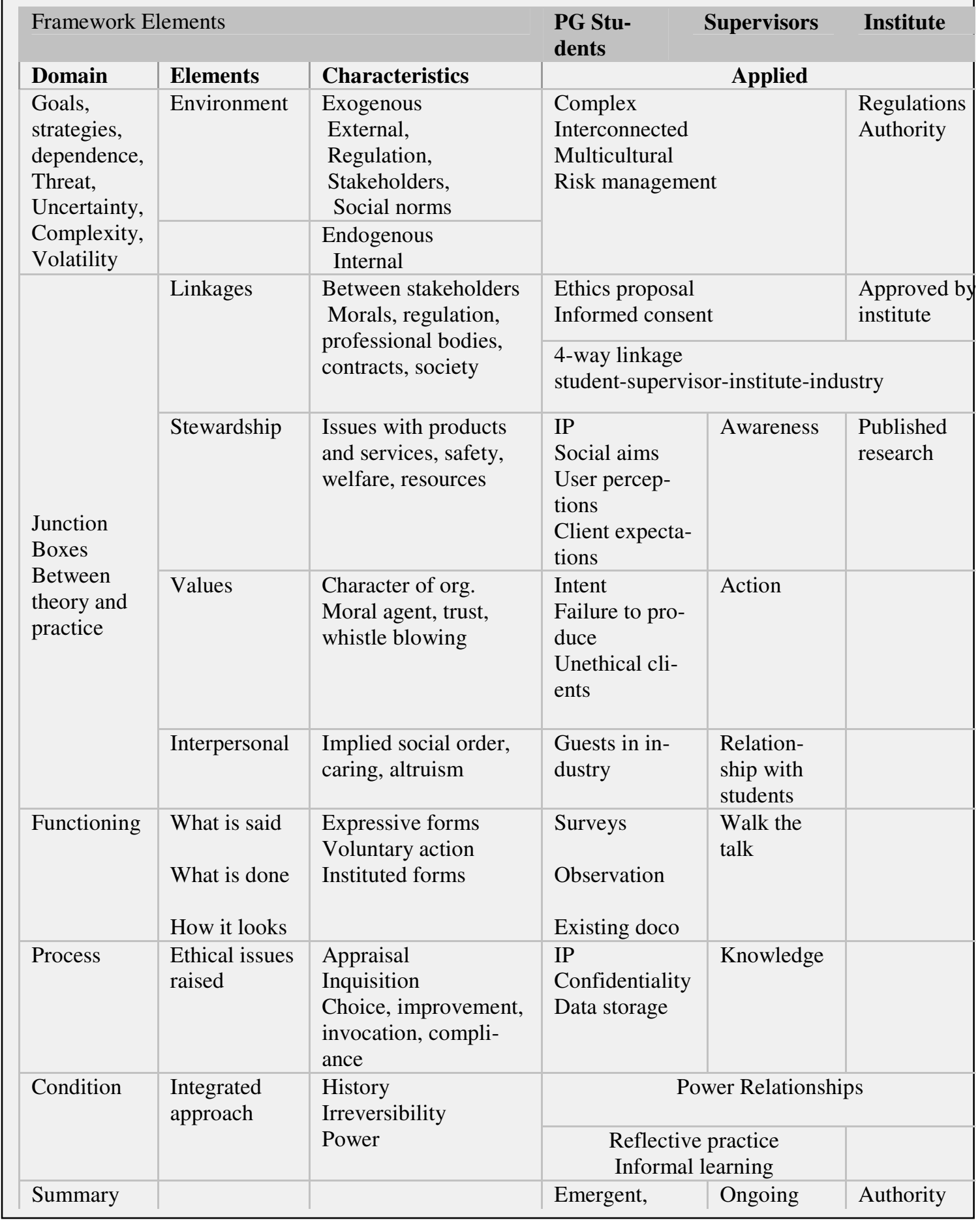

multicultural mix of postgraduate students in the Masters of Computing (Mcomp) program, it is wise to bring to surface the underlying and often un-stated assumptions.

\section{The PG ethical environment}

The ethical environment in postgraduate research is situated within the wider environment of the computing and information technology discipline in UNITEC. Postgraduate research also lies 
within the ethical environment of the client organization and the Information Technology profession (Figure 1). The institution environment is governed formally by a code of ethical conduct; the information technology profession by recognized codes of ethics and the client organization by its own code of ethical behavior. Some client organizations, particularly large organizations are more likely to have their own formal ethical procedures and policies. There have been instances of student research projects being thwarted by organizational ethical considerations, especially for students researching within their own organization.

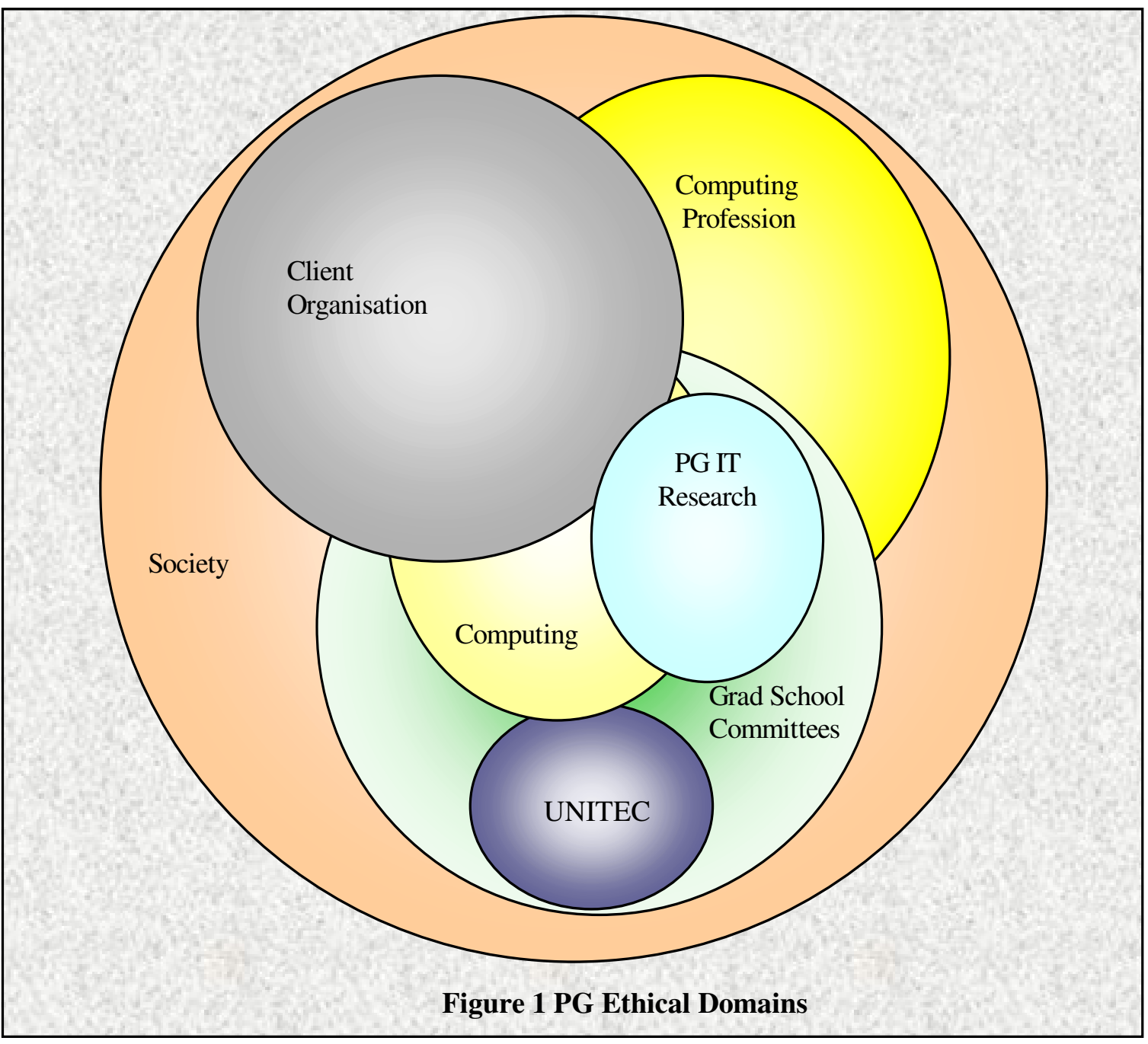

\section{Links between PG ethical domains}

To establish a link between these various ethical domains, a formal ethics proposal is drawn up for each dissertation or thesis (Table 1). This ethics proposal establishes terms of reference for all concerned, and articulates roles and rights. This formal ethics proposal is approved by the institution's ethics committee, either by a delegated checklist to the Mcomp program director or by the full committee. Approval takes place within the academic administrative domain for proposals facing ethical dilemmas with culture, intellectual property or privacy. Approval takes place within the Mcomp program for all other proposals. 


\section{The three ethical spheres in PG research}

The three ethical spheres in postgraduate research ethics in computing are: the ethical stance of the organization with which students interact, the information technology profession and its professional code of ethics and the academic code of ethics for students engaged in research in a tertiary institution. At times these three spheres make for 'uneasy bedfellows'. Each postgraduate student is required to submit a formal research proposal to the graduate school academic committee for approval. The research proposal together with the formal ethics approval constitutes a contract clarifying the interaction with the participant organization. This contract provides legal protection for both organization and student should an ethical breach occur. Fielden (2003) has discovered that ethical dilemmas are most likely to occur as boundaries between spheres are crossed.

\section{Linkage}

In this framework, ethical issues relating to external stakeholders and interest groups are described in the various ethical domains as linkages. These include moral dimensions of dealings with government and political organizations; regulation of professional conduct; membership of professional bodies; contractual relations; and the position of the organization within the community.

\section{Linkages for PG research}

In developing professional linkages, the ethics proposal, informed consent and client letter that establishes a contract between the postgraduate student, client and the institution are important. Organisations that liaise with the institution via student research projects have the opportunity to find out student abilities. At the same time, ethical links are established between industry and the institution. As postgraduate research is a learning process, links with professional organisations may not materialise at this stage. Government funded research projects have not been part of Mcomp research projects and so are not considered in this discussion.

\section{Stewardship}

According to Nicholson's (1994) four-fold framework, stewardship involves issues arising from the organization's products and services and the ethical values attached to the systems that produce them. These include considerations of plant safety, employee welfare, environment protection, use of natural resources, the social aims of company products and the consequences of their use.

\section{Stewardship on PG research}

Stewardship considerations in postgraduate research in applied computing are usually restricted to the use of intellectual property rather than physical or environmental issues. Stewardship may also involve social aims of the organization and its resultant consequences. Mcomp research projects may include social dimensions, client, user and/or stakeholder perceptions. This means that the ethical dimension of stewardship must be considered in educating and guiding students through their research projects.

Ethical dilemmas have arisen when client organizations have unrealistic expectations of postgraduate research findings. Even though a contract is in place, often the expectation is that research findings would reap immediate economic, social or political benefits.

The institution in turn uses publicity gained from completed postgraduate research as a marketing tool to advertise what has been achieved in published research profiles, publications and annual research reports. 


\section{Values}

Values are the ethical character of the organization (Nicholson, 1994); they act as a moral agent for the evaluation of actions and expressions on the basis of intent and moral awareness, rather than consequences. Evaluation of such qualities as altruism, openness, trust and trustworthiness are considered here (Baase, 1997; Klein \& Hirscheim, 1996; Moore, 1995). Actions, such as information disclosure, whistle blowing and bribery are judged as if they reveal the moral essence of the organization or its agents (Edgar, 1997).

\section{Ethical values for PG researchers}

In considering values for a postgraduate researcher in computing, it may be intent rather than consequences that is the issue. If the intent of the postgraduate researcher is not aligned with the academic intent for the thesis or dissertation, then there would be a mismatch in values between student and institution. A moral dilemma is posed when a postgraduate student does not produce for the client organization what has been set out in the contract. This is the research proposal for postgraduate students. The underlying assumption is that postgraduate students will take research seriously. There is a moral obligation to clients to achieve what has been stated in the research proposal. Values may also be an issue when unethical work practices are revealed in client organizations.

\section{Interpersonal}

Interpersonal considerations encompass the implied social order of moral conduct, such as caring behavior, concern for the personal development of people, encouraging corporate citizenship among members, the responsible use or sharing of power, equitable payment and the treatment of minorities.

\section{Interpersonal considerations for PG research}

Interpersonal considerations are of paramount importance to the qualitative researcher in applied computing. Stake (2000, p. 440) states, "Qualitative researchers are guests in the private spaces of the world."

The implied social order is in the relationship between the postgraduate student and supervisor, between student and clients, and between staff and clients. Although there is an obvious power relationship between supervisor and student, it is not uncommon for a close working relationship to develop between the postgraduate student and the staff supervisor.

\section{Ethical domain summary}

The four domains of linkage, stewardship, values and interpersonal behavior can be seen as "junction boxes" between ethical theory and environmental contingencies. Ethical theory is said to be concerned with issues of rights and duties (linkages), utilities (stewardship), conscience (values) and justice (interpersonal). On the other side of the junction box are contingencies of the organization's external relations (linkages), environmental interdependencies (stewardship), workforce composition (values) and organizational structure and culture (interpersonal). These classes are not assumed to be mutually exclusive, but distinct, as moral conduct in one domain does not necessitate moral conduct in another. These indeed may cause points of tension between client organizations and the academic world of research.

\section{Ethical Functioning}

The second element of Nicholson's (1994) four-fold framework is ethical functioning. Moral appraisal of organizations or their agents is likely to be based on three kinds of evidence - what they 
say, what they do and how they look. What they say is the realm of expressive forms: symbolic or communication acts which affirm values. What they do is the realm of voluntary action: behaviors that reflect acceptance of responsibility, moral choice and freedom of action. How they look is the realm of instituted forms; structured roles, rules and systems that have explicit ethical purpose or reference.

For individuals, expressive forms are moral attitudes or beliefs. At the organizational level, expressive forms constitute much of the substance of company culture: mission statement, sanctioned behavior and the content of everyday discourse. Voluntary action includes acts of choice and preference, for example acts which initiate, block or support ethical action. At the organizational level, ethical functioning takes the form of implemented strategy, stakeholder dealings, image promotion, and the rewards and punishments administered to employees.

\section{Ethical functioning for PG research}

In postgraduate research, ethical considerations are largely focussed on how data is gathered. Interviews gather data from what people say in either a structured or unstructured format. Questionnaires gather data on what people think and feel they can divulge in written form. Data gathered by observation falls under voluntary action; existing organisational documentation used as data is in instituted forms.

\section{Instituted forms}

The third component of ethical functioning is instituted forms. At the exogenous level, these are moral forces bearing upon a person: the moral responsibilities enshrined in roles, rules, codes and methods. At the organizational level, instituted forms are the presence or absence of rules. Offices, departments and decision-making entities have explicit responsibility for ethical domains such as welfare provision, medical care, equal opportunities and environmental protection. This triad is not just whether organizations walk as they talk, it is also whether they are institutionally equipped to do so. Ethical functioning is depicted in terms of interaction between values, behaviors and structures.

\section{Ethical functioning for supervisors}

"Walking the talk" in ethical functioning is reinforced by supervisors acting as ethical mentors as well as academics within the computing profession. Student voluntary action is brought to consciousness when ethical dilemmas arise, because of differing documentation requirements between institution and client, differences in moral responsibilities between academia and industry, multiple roles played by students and participants, and differences in ethical domain 'language'.

\section{Ethical Process}

The third element of Nicholson's (1994) four-fold framework is the ethical process. Ethical process is the means by which ethical issues are raised to awareness. An instance of an ethical issue is the morality of a belief, action or institutional form being considered by an actor or observer. Ethical processes may be:

1. Psychological appraisal. This may be introspection or moral evaluation;

2. Inquisition. These may be attempts to arrive at a causal analysis of an event;

3. Choice. (This usually takes the form of debate between courses of action;

4. Improvement such as pursuit of quality;

5. Invocation in which an event is placed an event within the context of a moral order; or 
6. Compliance where there is requirement to comply with some ethical precept.

\section{Ethical process for PG research}

Ethical dilemmas that arise during the research process involve issues of intellectual property, confidentiality and data storage. Qualitative research takes the postgraduate researcher into emergent and unexpected ethical problems in the research process.

A student researching issues within electronic banking may be bound by an organizational confidentiality clause and therefore nor permitted to report exact numeric results. This then becomes a dilemma in writing the thesis or dissertation particularly for a quantitative study based on data mining as the data gathering method because examiners look for exact results in such quantitative statistical studies.

\section{Ethical Condition}

The fourth element of Nicholson's (1994) four-fold framework is ethical condition. Ethical condition is an integrated approach to ethical functioning. Ethical condition also looks at history and considers if ethical awareness is irreversible; that is, can integrity decline and reputation decay. Ethical condition relates to egocentric morality where there is differential power relationship between the academic institution, the client organization and the postgraduate student. Ethical functioning is governed by the norm of reciprocity where social responsibility bounded by prevailing values and norms of the host culture, relativism and moral order.

\section{Ethical condition for PG research}

Differential power relationships are at the heart of many postgraduate research studies. For instance, a postgraduate student researching in her/his own organization that also happens to be the academic institution of study is in the midst of complex power differentials. The student, who is also a program director for another study program and an associate dean in another school interacts with a colleague as participant who is also a program director (yet another school) and a member of the institution's ethics committee. The student enters the research interview process with the assumption that her/his participant will cooperate as a colleague on a similar organizational level. Instead the participant queried the ethical condition under which the interview was to be conducted. The power relationship moved from one of assumed equality as colleagues, from one of 'power in knowledge of the particular research project' held by the student to one of power vested in the participant as a member of the ethics committee.

Postgraduate researchers in learning research ethics, acquire knowledge about ethical condition that happens during the research process as a reflective practice.

Informal learning about ethical condition is an ongoing and evolutionary activity. Each time an ethical issue arises, a difference in ethical rules applies from the various domains; or each time a personality conflict arises, an opportunity to gain awareness of the ethical condition and its implication for the research process is present. As a dissertation or theses is of limited duration, feedback from one postgraduate student to another does not necessarily go back to that cohort, but rather to students enrolling in the following year via the knowledge developed and disseminated by supervisors, program director and the institution. Ethical condition then becomes an everincreasing body of knowledge.

\section{Some Reflections}

In this paper, Nicholson's (1994) four-fold framework has been applied to the process of learning to be an ethical researcher in computing in a postgraduate degree. Placing emphasis on ethical 
considerations during the research process provides a method of balancing human and technical considerations in becoming a competent researcher in computing.

These ethical considerations are most important when students are undertaking qualitative research where ethical boundaries and dilemmas may not be clearly articulated (Heron, 1996).

Including instruction in ethics within then taught component of the Mcomp program is only a first step in raising awareness of ethical issues in postgraduate research. Providing ongoing support for students through proposal preparation, during the research process and writing up results is essential. Dealing with issues as they arise also adds to the ethics knowledge pool for current and future students and supervisors. Ongoing training and support for supervisors is one way in which knowledge and experience gained about ethical dilemmas may be disseminated to future cohorts of students.

\section{Future Directions}

Ongoing supervision training in dealing with ethical dilemmas expands the knowledge and skills for all postgraduate supervisors - not just those involved in individual ethical incidents. Initial instruction in the multi-dimensional nature of research ethics in computing should be augmented by strategies employed to deal with ethical dilemmas as they arise. Having aware knowledge of the ethical elements involved via a deconstructive tool such as Nicholson's (1994) four-fold framework aids the learning process in researching and supervising in the Mcomp program. This also implies that postgraduate lecturers are also supervisors and that all involved in teaching or supervising on the Mcomp program take part in ongoing ethical training.

\section{Conclusion}

Developing a greater flexibility in thinking styles to include knowledge about ethical issues is a necessary skill for information systems professionals moving into a rapidly changing technical and social working world. A more balanced and mature view of the role of the computing researcher is necessary to deal with ethical issues alongside technical expertise.

A deeper understanding of self and others in complex human activity systems occurs when ethical dilemmas are deconstructed. People are placed at the centre of research ethics rather than technology; here, and a diverse set of professional skills are acquired which forms the basis of a continuing education, knowledge and wisdom in dealing with ethical dilemmas in a technicallydriven world.

\section{References}

Baase, S. (1997). A gift of fire: Social, legal, and ethical issues in computing. New Jersey: Prentice-Hall.

Cassidy, A. (1998). A practical guide to information systems strategic planning. Florida: St Lucie Press.

Edgar, S. L. (1997). Morality and machines: Perspectives on computer ethics. USA: Jones \& Bartlett.

Fielden, K. (2003). System boundary issues for informed consent in action research: A birdseye view. Proceedings of ANZSYS2003, Melbourne, November 18-20.

Heron, J. (1996). Co-operative inquiry: Research into the human condition. London: Sage.

Hirscheim, R., Klein, H. K., \& Lytinnen, K. (1995). Research ethics: Conceptual and philosophical foundations. Great Britain: Cambridge Institution Press.

Klein, H. K. \& Hirschheim, R. (1996, September 26). The Rationality of Value Choices in Research Ethics. Foundations of Information Systems. Retrieved from http://www.bauer.uh.edu/parks/fis/kantpap.htm 
Moore, T. (1995). Caring for the Soul in Business. In B. De Foore \& J. Renesch (Eds.), Rediscovering the soul of business (pp. 342 - 356). San Francisco: New Leaders Press.

Nicholson, N. (1994). Ethics in organisations: A framework for theory and research. Journal of Business Ethics, 13, 581-596.

Pierce, M. A. \& Henry, J. W. (1996). Computer ethics: The role of the personal, informal and forma; Codes. Journal of Business Ethics, 15 (4), 425-437.

Romm, C. T. \& Wong, J. (1998, November 4). Ethical dilemmas in organisational web site development. Foundation for Information Systems. Retrieved from http://www.bauer.uh.edu/parks/fis/romm.htm

Stake, R. E. (2000). Case studies. In N.K. Denzin \& Y.S. Lincoln (Eds.), Handbook of qualitative research $\left(2^{\text {nd }}\right.$ ed., 435-454). Thousand Oaks, CA: Sage.

Teichman, J. (1995). Social ethics. Great Britain: Blackwell.

\section{Acknowledgements}

Thanks to May Goh for her invaluable editing assistance.

\section{Biography}

Dr. Kay Fielden is an associate professor in Computing in the School of Computing and Information Technology, UNITEC Institute of Technology, Auckland, New Zealand. She is also the research coordinator for the school and has supervised many postgraduate students. 